\title{
Surgery of a Posterior Communicating Artery Aneurysm with Fetal-Type Circulation
}

\section{Cirurgia de um aneurisma da artéria comunicante posterior com circulação do tipo fetal}

\author{
Nicolás González ${ }^{1}$ Manuel Morales ${ }^{1}$ Franco Ravera ${ }^{1}$ Arturo Ruiz-aburto ${ }^{1}$ Juan Vásquez ${ }^{1}$ \\ José Muller ${ }^{1}$ Jhon Mosquera ${ }^{1}$ Rodrigo Zapata ${ }^{1}$ \\ ${ }^{1}$ Department of Neurosurgery, Hospital Regional Rancagua, \\ Rancagua, Chile \\ Address for correspondence Nicolás González, MD, Hospital Regional \\ Rancagua, Rancagua, Av. Libertador Bernardo O'Higgins 3065, \\ Rancagua, Chile (e-mail: nicolasgonzalez28@gmail.com).
}

Arq Bras Neurocir 2018;37:154-156.

\begin{abstract}
Keyowords

- aneurysm

- posterior communicating artery

- circle of Willis

- microsurgery

\section{Resumo}

Palavras-chave

- aneurisma

- artéria comunicante posterior

- círculo de Willis

- microcirurgia

Inadvertent occlusion of a fetal-type posterior communicating artery in aneurysm surgery could result in posterior circulation infarction and neurological morbidity. The case of a patient with an unruptured posterior communicating artery aneurysm with lateral projection and a fetal-type posterior communicating artery is presented. The utility of the carotid-oculomotor window as a surgical corridor to safely find the fetaltype posterior communicating artery is discussed.

A oclusão da artéria comunicante posterior do tipo fetal em cirurgia de aneurisma pode resultar em infarto da circulação posterior e morbidade neurológica. Apresentamos o caso de um paciente com aneurisma não roto da artéria comunicante posterior com projeção lateral e uma artéria comunicante posterior do tipo fetal. Discutimos a utilidade da janela carótida-oculomotora como um corredor cirúrgico para encontrar com segurança a artéria comunicante posterior do tipo fetal.
\end{abstract}

\section{Introduction}

A fetal configuration of the circle of Willis is seen in up to $17.5 \%$ of an adult patient population. ${ }^{1}$ Compromise of a fetaltype posterior communicating artery (PCOMM) or its perforators by surgical clipping could result in posterior circulation infarction and neurological morbidity. ${ }^{2,3}$ The technical considerations in the treatment of a patient with a PCOMM aneurysm with lateral projection and a fetal-type PCOMM artery are presented.

received

March 23, 2018

accepted

May 8, 2018

published online

July 9, 2018 $10.1055 / \mathrm{s}-0038-1661357$ ISSN 0103-5355.

\section{Case}

A 65-year-old female patient was admitted to our emergency unit with a sudden onset of headache and diplopia. Physical examination revealed a left-sided complete third nerve palsy. The computed tomography (CT) scan was negative for subarachnoid hemorrhage. The computed tomography angiography (CTA) (-Fig. 1) revealed a left $4.9 \mathrm{~mm} \times 9 \mathrm{~mm}$ unruptured left PCOMM aneurysm with a lateral projection. Ipsilateral fetal configuration of the circle of Willis was

Copyright @ 2018 by Thieme Revinter Publicações Ltda, Rio de Janeiro, Brazil

License terms 


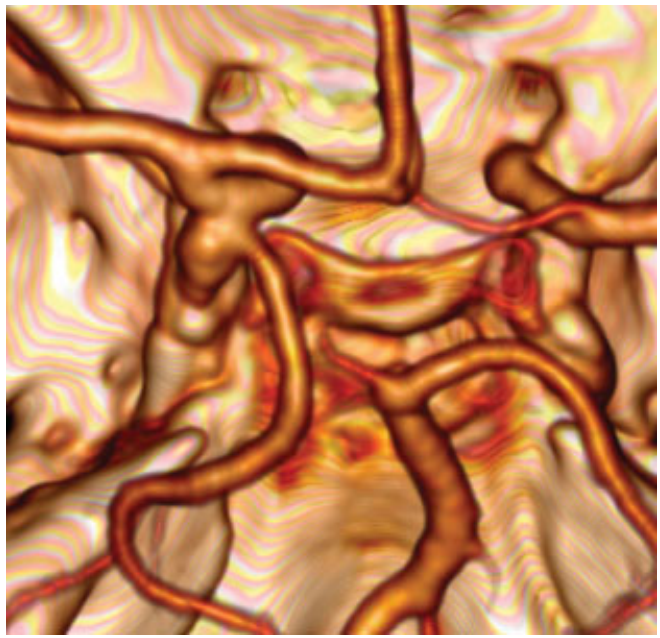

Fig. 1 Preoperative computed tomography angiography.

observed, with a large hyperplastic PCOMM of $13 \mathrm{~mm}$ length and $2.5 \mathrm{~mm}$ width, and a hypoplastic P1 segment of the posterior cerebral artery.

\section{Surgical Technique}

A classic pterional craniotomy was performed on the left side. Under the surgical microscope, initial arachnoid dissection of the optic-carotid cistern allowed cerebrospinal fluid aspiration and brain relaxation. Exposure of the PCOMM segment of the internal carotid artery (ICA) revealed the aneurysm ( - Fig. 2A), but visualization of the PCOMM origin was not possible. At this point, to allow visualization of the PCOMM it was necessary to do a proximal opening of the Sylvian fissure, to reveal the carotid-oculomotor window $(\mathrm{CoW})$. As previously reported, ${ }^{3}$ temporal lobe retraction should be avoided to prevent aneurysm rupture. Pilot clipping with a $9 \mathrm{~mm}$ straight clip was performed (- Fig. 2B) to increase the safety of Sylvian fissure dissection. In the CoW ( - Fig. 2C, D) it was possible to find the PCOMM origin and the perforators. Proximal control at the ophthalmic segment and at the PCOMM segment (-Fig. 2E) allowed aneurysm softening and clip repositioning, under direct visualization of the PCOMM artery (- Fig. 2F) and anterior choroidal arteries. Doppler sonography confirmed vascular flow. The patient had a good postoperative course without complications and was discharged with ongoing improvement of her third nerve palsy.

\section{Discussion}

In a non-fetal configuration of the circle of Willis, the PCOMM is found at the interpeduncular cistern in the opticocarotid window, ${ }^{4}$ and its origin is observed as a knuckle on the posterolateral carotid wall, just proximal to the neck of the aneurysm, with a lateral to medial path from the ICA to the posterior cerebral artery. ${ }^{5}$
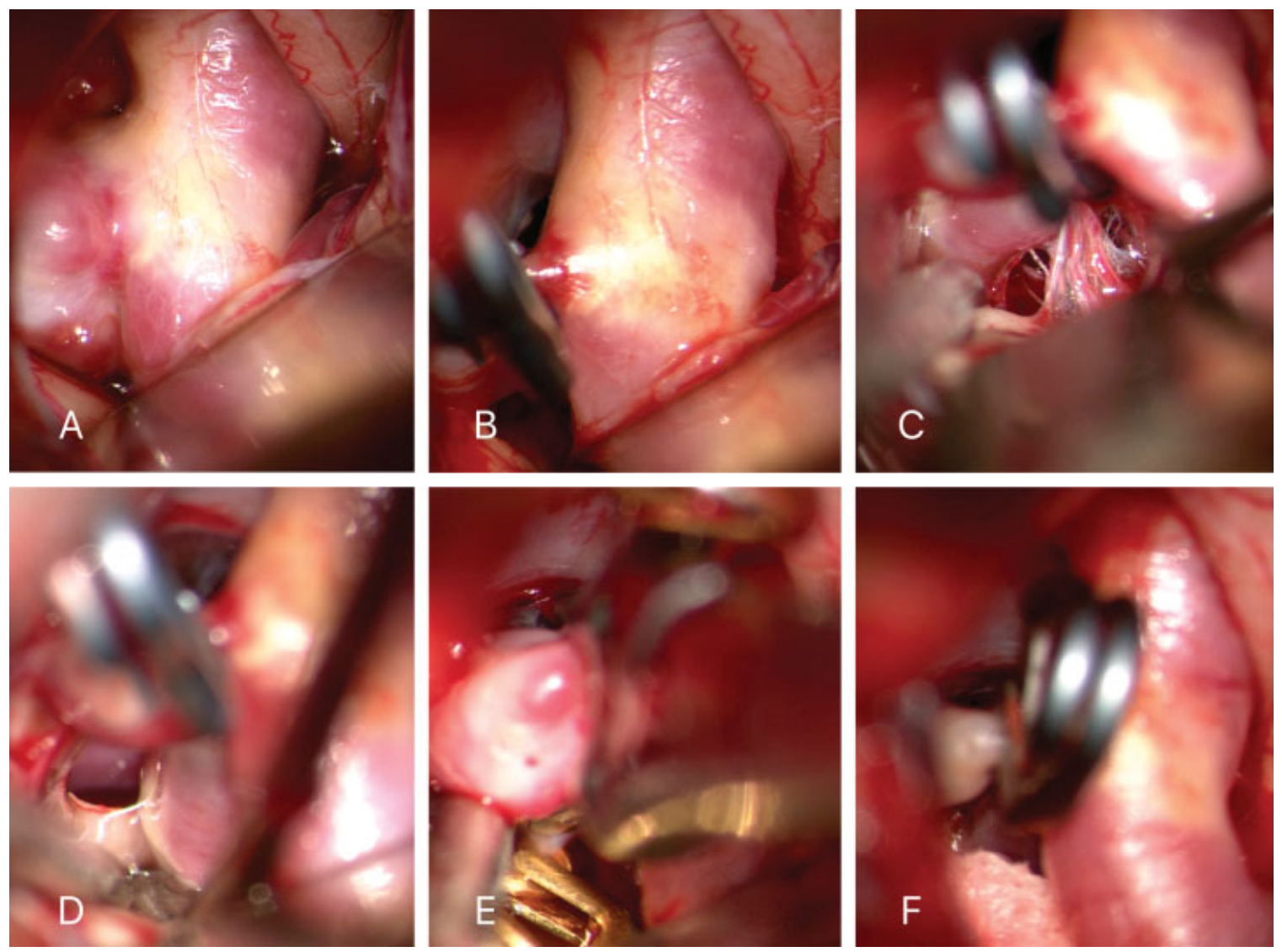

Fig. 2 Surgical technique. 
Surgery of PCOMM aneurysms with a fetal configuration of the circle of Willis endangers inadvertent occlusion of the PCOMM, because of its medial to lateral projection. ${ }^{5}$ In these cases, a laterally projecting aneurysm may hide the PCOMM origin and perforators. In this scenario, we believe it is necessary to do a careful proximal dissection of the Sylvian fissure, avoiding temporal retraction, to fully expose the CoW: the space between the ICA medially, the oculomotor nerve laterally, and the uncus posteriorly. ${ }^{6}$ The CoW has been traditionally mentioned as providing access to the basilar apex aneurysm, 6,7 but should also be considered as a surgical corridor in cases of fetal type PCOMM. This surgical strategy achieves three goals: to gain proximal control at the PCOMM, to fully observe the PCOMM during final clip application, and to confirm patency of PCOMM and perforators. Micro doppler ultrasound ${ }^{8}$ and/or near infrared indocyanine green videoangiography ${ }^{9}$ are useful tools that may be utilized to confirm vascular flow. Additionally, in cases of third nerve palsy, nerve decompression may be performed, although it has been reported that oculomotor nerve palsy improves, in most cases with clipping and without need of nerve decompression. ${ }^{10,11}$

Anterior clinoidectomy ${ }^{12,13}$ and/or anterior petroclinoid fold $^{14}$ release may be necessary in cases when the intraoperative view of the neck of the aneurysm is obstructed by the anterior clinoid process, as in cases of short length of the ICA.

\section{Conclusion}

A laterally projecting PCOMM aneurysm may hide the PCOMM origin in a fetal configuration of the circle of Willis. In these cases, careful proximal Sylvian fissure dissection and exposure of the carotid oculomotor window are needed to expose the PCOMM artery, gain proximal control, and to confirm patency after clipping.

Conflicts of Interest

The authors declare that they have no conflicts of interest.

\section{References}

1 Beumer D, Delwel EJ, Kleinrensink GJ, Akouri S, Torres A, Krisht AF. The perforator-free zone of the posterior communicating artery and its relevance in approaches to the interpeduncular cistern, especially the transcavernous approach: an anatomic study. Neurosurgery 2007;61(05, Suppl 2):187-191, discussion 191-192
2 Golshani K, Ferrell A, Zomorodi A, Smith TP, Britz GW. A review of the management of posterior communicating artery aneurysms in the modern era. Surg Neurol Int 2010;1:88

3 Thiarawat P, Jahromi BR, Kozyrev DA, et al. Microneurosurgical Management of Posterior Communicating Artery Aneurysm: A Contemporary Series from Helsinki. World Neurosurg 2017; 101:379-388

4 Martins C, Yasuda A, Campero A, Rhoton AL Jr. Microsurgical anatomy of the oculomotor cistern. Neurosurgery 2006;58(04, Suppl 2):ONS-220-ONS-227, discussion ONS-227-ONS-228

5 González-Darder JM, Quilis-Quesada V, Talamantes-Escribá F, Botella-Maciá L, Verdú-López F. Microsurgical Relations between Internal Carotid Artery-Posterior Communicating Artery (ICAPComA) Segment Aneurysms and Skull Base: An Anatomoclinical Study. J Neurol Surg B Skull Base 2012;73(05):337-341

6 Youssef AS, Abdel Aziz KM, Kim EY, Keller JT, Zuccarello M, van Loveren HR. The carotid-oculomotor window in exposure of upper basilar artery aneurysms: a cadaveric morphometric study. Neurosurgery 2004;54(05):1181-1187, discussion 1187-1189

7 Kim YD, Elhadi AM, Mendes GA, et al. Quantitative study of the opticocarotid and carotid-oculomotor windows for the interpeduncular fossa, before and after internal carotid artery mobilization and posterior communicating division. Neurosurgery 2015; 11(Suppl 2):162-179, discussion 179-180

8 Kapsalaki EZ, Lee GP, Robinson JS III, Grigorian AA, Fountas KN. The role of intraoperative micro-Doppler ultrasound in verifying proper clip placement in intracranial aneurysm surgery. J Clin Neurosci 2008;15(02):153-157

9 Sharma M, Ambekar S, Ahmed O, et al. The utility and limitations of intraoperative near-infrared indocyanine green videoangiography in aneurysm surgery. World Neurosurg 2014;82(05): e607-e613

10 Güresir E, Schuss P, Seifert V, Vatter H. Oculomotor nerve palsy by posterior communicating artery aneurysms: influence of surgical strategy on recovery. J Neurosurg 2012;117(05):904-910

11 Anan M, Nagai Y, Fudaba H, et al. Third nerve palsy caused by compression of the posterior communicating artery aneurysm does not depend on the size of the aneurysm, but on the distance between the ICA and the anterior-posterior clinoid process. Clin Neurol Neurosurg 2014;123:169-173

12 Park SK, Shin YS, Lim YC, Chung J. Preoperative predictive value of the necessity for anterior clinoidectomy in posterior communicating artery aneurysm clipping. Neurosurgery 2009;65(02): 281-285, discussion 285-286

13 Sade B, Kweon CY, Evans JJ, Lee JH. Enhanced exposure of caroticooculomotor triangle following extradural anterior clinoidectomy: a comparative anatomical study. Skull Base 2005;15(03):157-161 , discussion 161-162

$14 \mathrm{Kim}$ JH, Kim JM, Cheong JH, Bak KH, Kim CH. Simple anterior petroclinoid fold resection in the treatment of low-lying internal carotid-posterior communicating artery aneurysms. Surg Neurol 2009;72(02):142-145 